\title{
Overview on Pharmaceutical Formulation and Drug Design
}

Bassam Abdul Rasool Hassan*

Clinical Pharmacy Discipline, School of Pharmaceutical Sciences, University of Sains Malaysia, 11800, Minden, Penang, Malaysia

\section{Definition}

\section{Pharmaceutical formulation}

It is the processes in which different chemical substances i.e., active chemical substances will combined together to produce a medical compound i.e., medical drug.

\section{Drug design}

It is the process of producing or invention of novel and/ or new medical product, the design of this new product completely based on the knowledge of biological target. Moreover, this process sometimes known as or called rational drug design.

\section{Background}

\section{For pharmaceutical formulation}

This process involves production of drug which characterized by two things: first it must be a stable product, second it must be acceptable to the patient who will use it. Besides that in case of synthesis of an oral medication (tablet or capsule) it will contain a variety of ingredients besides the drug itself so it is an obligate matter to be sure that all of these ingredients must be incorporate with each other. Therefore it is very important to do a lot of formulation studies in order to detect the point of incorporation. Besides that formulation studies must focus on other factors like particle size, polymorphism, $\mathrm{pH}$ and solubility, in order to check whether these factors will effect on bioavailability of the drug or not.

\section{For drug design}

In case of drugs design, computer modeling techniques consider as a very important factor in this field. The phrase "drug design" precisely means design of small molecule that will bind tightly to the required target i.e., ligand. The target will refer either to a particular metabolic or signaling pathway that is specific to a disease condition or pathology or to the infectivity or survival of a microbial pathogen. But there are important points which need to optimized first before a ligand can consider safe and effective, these points are metabolic half-life, bioavailability and drug side effects.

\section{Classifications for Pharmaceutical Formulation and Drug Design \\ Drug design}

There are two major types or classifications of drug design. The first is called as ligand-based drug design and the second, structure-based drug design.

- Ligand-based drug design- In this branch or type of pharmaceutical formulation the design of the drug will be made or built depends on the knowledge of what binds to it.

- Structure-based- while this type drug design will depend on the information related with the three dimensional structure of the biological target these information will be gotten by using methods like X-ray or NMR.

\section{Pharmaceutical formulation}

There are two types or classifications for Pharmaceutical Formulation, these types are the following:

- Oral formulation- The most important characteristic for oral formulation it must be overcome the problems which associated with oral administration. The most critical problem is rate of drug solubility i.e., the active ingredient of the drug must be soluble in aqueous solution in a constant rate. This point can be controlled through some factors like particle size and crystal form. The oral formulation divided in two parts which are: A- Tablet form \& B- Capsule form.

- Topical medication forms- This type include several parts as the following:

- Cream, B- Ointment, C- Gel, D- Paste, and E- Powder.

\section{Conclusion}

Therefore it is a very important point for the open access journals to encourage researchers to work hard in order to develop more drugs and treatments in order to get the best solubility and effectiveness.

*Corresponding author: Bassam Abdul Rasool Hassan, Clinical Pharmacy Discipline, School of Pharmaceutical Sciences, University of Sains Malaysia, 11800, Minden, Penang, Malaysia, Tel: (+6)016-423-0950; E-mail: bassamsunny@yahoo.com

Received December 08, 2012; Accepted December 10, 2012; Published December 12, 2012

Citation: Rasool Hassan BA (2012) Overview on Pharmaceutical Formulation and Drug Design. Pharmaceut Anal Acta 3: e140. doi:10.4172/2153-2435.1000e140

Copyright: ( 2012 Rasool Hassan BA. This is an open-access article distributed under the terms of the Creative Commons Attribution License, which permits unrestricted use, distribution, and reproduction in any medium, provided the original author and source are credited. 